\title{
ST LUCIA
}

Area: 616 sq. $\mathrm{km}$
Population: 123,300
Capital: Castries

Governor-General: Sir Allen Lewis

Emergency services: 999

The St Lucia Police Force is headed by a Commissioner, who is responsible to the Premier, and has a personnel strength of 290. It includes the Port Police and the Training Division, and is in charge of the Fire Brigade.

Headquarters is at Castries, and there are police stations at Anse-la-Raye, Canaries, Choiseul, Delaide, Dennery, Gross Islet, Laborie, Marigot Bay, Micoud, Soufriére and VieuxFort.

Police Headquarters, Bridge Street, Castries (22855)

Port Police, Jeremie Street, Castries (22371)

Training Division, La Toc (22443) 